\title{
Recruiting teachers online: marketing strategies and information dissemination practices of UK-based agencies
}

\author{
Rian de Villiers ${ }^{\mathrm{a} *}$ and Sue Books ${ }^{\mathrm{b}}$ \\ ${ }^{a}$ Department of Science, Mathematics and Technology Education, University of Pretoria, South \\ Africa; ${ }^{b}$ Department of Secondary Education, State University of New York, New Paltz, USA
}

*Corresponding author. Email: rian.devilliers@up.ac.za

\begin{abstract}
A review of the websites of 43 UK-based agencies that are recruiting teachers in South Africa and other countries finds that important information about what to expect often is missing. An analysis of the marketing strategies shows that agencies overall are promising schools thorough vetting of candidates and low fees, are promising prospective teachers good pay while inviting them to imagine an exciting life outside the classroom, and are assuring both that the agency can make the "right" match. The article concludes with a list of recommendations for candidates and for agencies.
\end{abstract}

Keywords: teacher migration; online teacher recruitment; overseas-trained teachers; UK; South Africa

Online teacher-recruitment agencies are competing vigorously in a globalized marketplace to match schools' needs to "cover" classes with young teachers' desires to spread their wings, and earn more money, in new and exciting places. By all accounts, this industry is thriving, especially in large "receiving" countries like the United Kingdom (UK). However, many overseas-trained teachers report that they are not well informed about the challenges awaiting them at typical inner city London schools (News 24 2005a). Mulvaney (2005) surveyed 100 South Africans teaching in London and found that more than half (54\%) felt they had been misled or not told the whole truth about conditions in the schools. One online recruitment agency, Teaching Personnel Ltd, warns explicitly,

Teachers - Don't get caught out! The teacher recruitment industry is very competitive. For whatever reason, not all consultants from the multitude of agencies out there will necessarily conduct business in your best interest. We will endeavour to make you aware of as many potential hurdles as possible to ensure that you are not taken advantage of and receive the correct advise $[\mathrm{sic}]$ at all times.

Direct marketing campaigns on university campuses are one of many strategies agencies use to recruit teachers, but these information sessions are generally very superficial. Prospective teachers therefore must rely on agency websites to obtain accurate and complete information before deciding to enter into an agreement. This study consequently is focused on primary questions:

- What information are UK-based recruitment agencies seeking overseas-trained teachers providing on their websites? 
- What online marketing strategies are these agencies using?

To address these questions, we reviewed the websites of 43 teacher-recruitment agencies selected on the basis of: (1) having a head office in the UK, and (2) recruiting overseas-trained teachers, including South Africans. ${ }^{1}$ We focused on South Africa because it is the main sending/resource country of teacher recruits to the UK.

The sections that follow provide an overview of teacher migration from South Africa to the UK, a more detailed description of the study, observations about the websites and marketing strategies of the online teacher-recruitment agencies, and concluding recommendations. Our purpose is neither to resolve the question of whether South Africans should be recruited to teach in the UK nor to make judgements about the practice of online teacher recruitment, but rather to raise awareness about how teachers are being recruited.

\section{Teacher migration from South Africa to the UK}

Among all 53 Commonwealth member countries, the UK has been especially successful in recruiting South African teachers. Whereas in 1997-1998 only 20 work permits were issued for South Africans to teach in the UK, by 2001-2002 the number of permits issued had risen drastically to 2297 (Jansen 2002). More than 5000 teachers left South Africa to work in the UK between 2001 and the end of 2003 (South African Broadcasting Corporation 2004). During these three years, the UK issued far more work permits to South Africans seeking to teach (6090) than to teachers from any other country (McNamara, Lewis, and Howson 2005). As many as 5000 South Africans reportedly are teaching in London alone at any given time (Asmal 2004; Bolowana 2005). UK Office of National Statistics 2007 data (Miller 2007) show that between July 1997 and July 2006, the largest three cohorts of overseas-trained teachers arrived from South Africa (10,474), Australia (8816), and the United States (5367). According to MacGregor (2008), South Africa loses some 4000 teachers a year to emigration. Bertram, Wedekind, and Muthukrishna (2007) found that 27.4\% of the 2004 and $23.4 \%$ of the 2005 samples of final-year student teachers in South Africa planned to teach abroad. Two thirds $(66 \%)$ of the teachers in both samples said they wanted to go to the UK. A national survey of South African trainee teachers found that $27 \%$ wanted to teach abroad after qualifying, and that $48 \%$ of teachers in the schools visited expressed interest in working overseas (Morgan, Sives, and Appleton 2006).

There is concern that recruitment of South Africans to teach abroad imposes a cost on the South African government since it subsidizes the training of teachers who subsequently work in other countries (Morgan, Sives, and Appleton 2006). However, the extent to which international mobility of teachers represents a "brain drain" depends partly on how long overseas-trained teachers stay abroad. Former South African Minister for Education Kader Asmal claims that many South African teachers choose to return after a year or two in the UK, and most return as better teachers (Asmal 2004). Morgan, Sives, and Appleton (2006) also found that teachers who returned to their home countries after teaching in the UK tended to have worked in the UK for only short periods. Both the mode and medium duration of stay was one year, with the mean being 17 months. Half the sample stayed overseas between 8 and 18 months; only $15 \%$ stayed for more than two years.

Bertram, Wedekind, and Muthukrishna (2007) found that the vast majority (more than $70 \%$ ) of trainee teachers intended to return to South Africa within two to four 
years, and more than half (56\%) intended to teach in South Africa when they returned. News 24 (2005b) reported that negative experiences in the UK caused many South Africans teaching abroad to lose all interest in teaching. Six of the eight South African teachers de Villiers (2004) interviewed in 2003 said that because of the poor salaries in South Africa, they would leave the teaching profession upon return. However, Manik (2007) found that 6 of the 12 returned teachers she interviewed were arranging a second migration to the UK.

Currently there is great concern about teacher shortages in South Africa. At least 1433 foreigners from African nations (Zimbabwe, Nigeria, Kenya, and Uganda) as well as the UK, the United States, New Zealand, Australia and the Indian subcontinent are now teaching in schools across South Africa (Govender 2007). The supply of newly qualified teachers is substantially below the number of teaching posts that become vacant each year. More than 17,000 teachers are leaving the teaching profession annually (Kruger 2008), and only about 6000 newly qualified teachers graduate per year. The Human Science Research Council (Bernstein 2007) estimated that by 2008 South Africa would need 15,090 teachers, assuming a learner-to-educator ratio of 40:1 for primary schools and 35:1 for secondary schools.

Appleton, Morgan, and Sives (2006) argue that international recruitment does not necessarily lead to harmful shortages of teachers in South Africa, but may "cream off" the more effective teachers. The national Department of Education has begun a campaign to recruit qualified foreign teachers to ease the critical shortage of science and mathematics teachers in South Africa. Reports indicate that South Africa needs almost 1500 mathematics and science teachers now, and this number is expected to rise (Busani 2008).

\section{South African teachers' experience in the UK}

Overseas-trained teachers working in the UK, including South Africans, have struggled with classroom management and disciplinary problems (Ochs 2003; de Villiers 2004; Mulvaney 2005; Manik 2007). These teachers have been surprised by learners' behaviour, by incidents of racism and other discrimination, and by physical and emotional abuse in classrooms in the UK (Manik 2007). Financial "surprises" are also common. Overseas-trained teachers told Sutherland and Rees (1995) and Ochs (2003) that the information they received about taxes and national insurance was inadequate. Supply teachers often are unaware that they are not paid for school and public holidays (de Villiers 2004).

Mulvaney (2005) found that 50 of the 100 teachers he surveyed had no school induction programme when they arrived for the first time, and de Villiers (2004) found that the induction programmes offered by the teacher-recruitment agencies were inadequate, at least from the perspective of the overseas-trained teachers. South Africans teaching in the UK told Mulvaney (2005) they were not properly informed by recruiting advertisements about the need to obtain Qualified Teacher Status (QTS), and told de Villiers (2004) that, without QTS, they then felt inferior because many of their colleagues did not regard them as fully qualified.

More than half the overseas-trained teachers McNamara, Lewis, and Howson (2007) surveyed between 2001 and 2006 (the majority of whom were from South Africa, Australia, and New Zealand) said they had sought social and emotional support during their stay in the UK. More than half also sought professional support related to teaching, professional development, or their status. About $20 \%$ encountered 
discrimination on the basis of race, nationality, or gender. Loneliness had a tremendous impact on the emotional well-being of many of the overseas-trained teachers. However, the most common complaint was the dreadful weather in the UK (Manik 2007)! In sum, the reported experiences of overseas-trained teachers in the UK underscore the need for teachers to obtain information that is as accurate and complete as possible before making a commitment to teach abroad.

\section{Methodology}

To ascertain the completeness of the information provided and the marketing strategies employed by UK-based agencies recruiting teachers online, we reviewed 43 websites, completed checklists for each with qualitative as well as quantitative data, then summarized the data on a spreadsheet and a comment sheet. The 52-item checklists were used to profile each agency, to record website content, and to summarize the "selling points" or "pitch" the agency made to both schools and teachers. For each agency, we looked to see if it had the Department for Education and Skills (DfES) Quality Mark (explained below), when it was established, when its website was updated, and whether it has overseas offices. We recorded information about each agency's application and vetting procedures, the fees it charges to schools, and the pay and special offers given to teachers. We also looked to see what information was provided about the UK education system, about living in the UK, and about support for teaching.

Under vetting procedures, we looked for information about interviewing procedures, teaching qualifications, teaching experience, UK entry requirements, and the need for a medical declaration and criminal record clearance. We also looked for requests for a curriculum vitae (CV) and referees. Under pay, we looked for information about scales, seasonal work, timesheets, and pension schemes, and for offers to provide banking assistance and tax advice. With respect to the UK education system, we looked for information about types of work, QTS, cultural diversity, special education needs, English as additional language, school types, school support staff, the UK National Curriculum, legal protections, assessment, and Key Stages in schools as well as whether education links were provided and whether acronyms were spelled out. We also looked for information about accommodation in the UK, transportation and food costs, phone advice, healthcare, and agency-planned social events. The "teaching support" category included information about agency induction programmes, schoolbased mentoring, professional development, and tips on behaviour management.

\section{Findings and discussion}

\section{Agency profiles}

In July 2002 the DfES introduced a voluntary code of conduct for agencies involved in the recruitment of teachers. The Department, in conjunction with the Recruitment and Employment Confederation (REC) (a trade association for employment agencies), awards a Quality Mark to agencies that adopt this code and pass an independent inspection and assessment. According to the REC website, agencies with the Quality Mark have met minimal standards related to methods of recruiting and interviewing teachers and of monitoring their performance, and have shown they are "stay[ing] at the forefront of changes in the teaching sector." Agencies must also commit to allowing teachers to complete their terms in their host countries, to reporting to the REC annually the number of teachers recruited, and to notifying target countries when 
recruitment campaigns are planned (DfES 2004). Agencies must reapply for the Quality Mark every two years. As of April 2008, only 22 (51\%) of the agencies reviewed had the Quality Mark and only eight indicated that it was valid from 2005-2007.

Just over half of the agency websites $(56 \%)$ provided the date the agency was established. Most were established between 1993 and 2004. This is not surprising since the UK suffered a crucial teacher loss in the late 1990s and early 2000s. Only 22 of the websites indicated when they were last updated. As of April 2008, only six (14\%) had been updated to 2008. The others were outdated. One was last updated in 2000 , one in 2005, three in 2006, and 10 in 2007. Eighteen of the recruitment agencies provided information about offices in other countries, primarily Australia (17 offices), South Africa (12 offices), New Zealand (10 offices), Canada (7 offices) and the United States (3 offices). Ten agencies listed three to four overseas offices.

\section{Vetting procedures}

Almost three-quarters (74\%) of the websites informed teachers that they would need a teaching qualification and criminal record clearance to teach abroad (Table 1). Seventy-two percent provided information about UK entry requirements, $70 \%$ made reference to a face-to-face interview, $67 \%$ assured potential clients that teachers' references would be checked, and 53\% asked teachers for a CV (Table 1). Very few agencies included advice on writing a CV (19\%) or interviewing (16\%). Fewer than half the websites listed "medical declaration" as part of the vetting procedure $(42 \%)$, suggested that teaching experience is required $(28 \%)$, or noted the need for proficiency in English (16\%).

\section{UK education system and teaching support}

More than half the websites $(60 \%)$ included useful educational links (Table 2). Overseas-trained teachers are regarded as unqualified teachers in the UK and receive a lower salary than teachers with QTS. However, only $42 \%$ of the agencies advised applicants about the importance of obtaining QTS for a permanent position. Only 18 websites (42\%) spelled out the acronyms they used, which undoubtedly confuse applicants unfamiliar with the terminology.

Although applicants need to be aware of the cultural diversity in the inner city schools, only $7 \%$ of the websites said anything about this. Overseas-trained teachers

Table 1. Vetting procedures used by UK-based online teacher-recruitment agencies $(n=43)$.

\begin{tabular}{lcc}
\hline Item & Number of agencies & Percentage \\
\hline Teaching qualification & 32 & $74 \%$ \\
Criminal record clearance & 32 & $74 \%$ \\
UK entry specifications & 31 & $72 \%$ \\
Face-to-face interview & 30 & $70 \%$ \\
Referees & 29 & $67 \%$ \\
CV & 22 & $53 \%$ \\
Medical declaration & 18 & $42 \%$ \\
Teaching experience & 12 & $28 \%$ \\
English proficiency & 7 & $16 \%$
\end{tabular}


Table 2. Information about the UK education system and teaching support provided by online teacher-recruitment agencies $(n=43)$.

\begin{tabular}{|c|c|c|}
\hline Item & Number of agencies & Percentage \\
\hline Education links & 26 & $60 \%$ \\
\hline Professional development* & 23 & $53 \%$ \\
\hline UK National Curriculum & 23 & $53 \%$ \\
\hline Agency induction programmes* & 19 & $44 \%$ \\
\hline Acronyms spelled out & 18 & $42 \%$ \\
\hline Qualified Teacher Status & 18 & $42 \%$ \\
\hline Types of work described & 16 & $37 \%$ \\
\hline Tips on behaviour management* & 14 & $33 \%$ \\
\hline Key Stages in schools & 13 & $30 \%$ \\
\hline School types & 12 & $28 \%$ \\
\hline Special education needs & 9 & $21 \%$ \\
\hline School support staff & 7 & $17 \%$ \\
\hline Methods of assessment & 5 & $12 \%$ \\
\hline School-based mentoring* & 4 & $9 \%$ \\
\hline Cultural diversity of pupils & 3 & $7 \%$ \\
\hline Legal protections for teachers & 2 & $5 \%$ \\
\hline English as additional language & 1 & $2 \%$ \\
\hline \multicolumn{3}{|l|}{ *Teaching support. } \\
\hline \multicolumn{3}{|c|}{$\begin{array}{l}\text { are likely to experience classroom management as one of their greatest challenges (de } \\
\text { Villiers 2004; Manik 2007; McNamara, Lewis, and Howson } 2007) \text {, but applicants } \\
\text { were not warned about this challenge. Only } 33 \% \text { of the websites made reference to or } \\
\text { provided tips on classroom management. Very few websites informed teachers about } \\
\text { special education needs }(21 \%) \text {, school support staff }(17 \%) \text {, methods of assessment } \\
(12 \%) \text {, school-based mentoring }(9 \%) \text {, legal protections }(5 \%) \text {, or pupils with English } \\
\text { as an additional language }(2 \%) \text {. }\end{array}$} \\
\hline
\end{tabular}

\section{Living in the $U K$}

The recruitment agencies overall are providing insufficient information about essential services and the cost of living in the UK. Information about accommodation, healthcare, transportation, food costs, phone service, and moving from South Africa was available on fewer than half the websites (Table 3).

\section{Testimonials}

Twenty-two (51\%) of the agencies included testimonials from teachers trained overseas. Where nationalities were given, Australia, Canada, Ghana, New Zealand, South Africa, the UK and the United States were listed. All the comments were positive, of course. These are representative:

caring ... best agency in London, top pay, always on time. Brilliant! go far beyond the call of duty to make sure their teachers are happy, comfortable and safe agent went out of his way to find me the right jobs operates more like a family than an office Always so friendly and efficient 
Table 3. Information about living in the UK provided by online teacher-recruitment agencies $(\mathrm{n}=43)$.

\begin{tabular}{lcc}
\hline Item & Number of agencies & Percentage \\
\hline Accommodation information & 21 & $49 \%$ \\
Accommodation assistance & 19 & $44 \%$ \\
Agency-planned social events & 14 & $33 \%$ \\
Healthcare & 11 & $26 \%$ \\
Transportation costs/distances & 10 & $23 \%$ \\
Moving from South Africa & 4 & $9 \%$ \\
Food costs & 3 & $7 \%$ \\
Phone advice & 2 & $5 \%$
\end{tabular}

\section{The 'pitch' to schools and teachers}

The online teacher-recruitment agencies overall are promising schools that they can deliver what amounts to a "high-quality product" at a good price and can do this efficiently and pleasantly. Most of the websites (55\%) assure prospective clients that the agency exercises "strict" or "stringent" quality control through initial vetting procedures, then offers continuing professional development as a way to monitor quality. The Premier Education website, for example, assures schools that candidates are not accepted "until we are satisfied that they are of the standard that we require." The Supply Desk website says its teachers have been not only "fully vetted and qualified," but also "fully informed of child protection issues." Teachweb promises simply no "nasty surprises!"

Almost all the agencies claim to provide this service at the lowest cost or at least at "competitive" rates, often while also paying the teachers well. However, only $16 \%$ provide specific information about their fees. NP Teaching, for example, says it "will not be beaten on price by a competing agency with a similar teacher to offer." Academics Ltd suggests, despite its "extremely competitive standard rates," that it will negotiate. Semester Recruitment leaves no doubt: "We will negotiate with you regarding charge rates!"

Many of the agencies promise to be "on call" around the clock and to act quickly, and almost all promise to be "friendly." These claims on the Teachers UK website, although more specific than many, suggest the scope of the services the teacherrecruitment agencies are promising:

Delivering a friendly, efficient and professional service is at the heart of what we do.... We therefore offer a call back guarantee to schools who use us, and will commit to contacting you within 30 minutes of taking a booking. ... We operate a staffed telephone service for schools which is open 24 hours, 7 days a week.

Although it is not clear what "friendliness" means in this context, the promise is pervasive: "We are flexible ... responsive ... friendly ... committed to your needs," Renaissance Education assures prospective clients. ITP Education Resourcing claims to be the friendliest of all: "much more school-friendly than our rivals!"

Even more common are agency assurances that they can make good matches. ITN Mark Education, for example, says it recommends only "candidates who have both the qualifications and personalities to fit in." Supply Desk similarly promises to "find a 
teacher who not only meets your job satisfaction, but who also matches the personality of your school," and Supply and Demand promises to place teachers "on the basis of suitability not just availability."

Other common selling points are claims about size or momentum, about business ethics, and about the teaching experience of agency staff or owners. Many of the agencies claim to be a "leading" recruitment agency, the "fastest growing," or the "largest." Teachweb notes that its "modern, fun and heavily advertised" website makes its "solid ethics clear to potential candidates." Academics Ltd says it provides "the most professional service available," in part because of its "ethical company culture." DLK Recruitment takes pride in "being reliable and honest at all times."

Other agencies stress their "passion" for education and link this to direct experience. Teachweb, for example, notes that its managing director:

still teaches in our client schools. He's a science teacher but get's [sic] stuck in to general cover too. He was a teacher and wants to remain one because he (and team) are passionate about providing the kind of service schools and children deserve.

A* Star Teachers similarly claims to have a passionate commitment to education - a "refreshing difference [that] results from A* Star Teachers being owned, managed and run by teachers and headteachers." Dream Education boasts that it is "directed and managed by educationalists that have spent their life at the chalk face of educational reality: in the classroom." However, the overriding message across the websites, stated perhaps most directly by Justteachers, is this: "We have a pool of premium teachers, pre-screened and ready to work for you."

The appeals to teachers resemble the appeals to schools. The agencies overall promise friendliness, support, and expert matchmaking to find "positions that suit you down to the ground" (ITN Mark Education). Almost all the agencies promise "excellent," "competitive," "the most generous," or "the best" rates of pay, and more than half $(53 \%)$ offer extra incentives, most commonly "recommend a friend" bonuses, "loyalty" bonuses, or both. Other incentives include free Criminal Records Bureau checks, discount shopping cards or gift vouchers, SIM cards, free use of the internet or a travel agency, or free personal accident cover and discounted insurance.

In addition, many of the agencies appeal to a desire for travel and adventure, and describe London or the UK as a wellspring of opportunity. A* Star Teachers, for example, notes that teaching in the UK provides

an opportunity to earn good travel money in a strong currency in a not-too-different culture that's well-positioned as a launch pad to the Europe [sic], Africa and beyond.... Whether you plan to snowboard the French Alps, sail the Mediterranean, go clubbing in Ibiza, run with the bulls in Pamplona, play the culture vulture through Europe or just chill out in Amsterdam, it is all within easy reach.

In its "Living in London" section, Global Education describes the city as: "a centre for all arts including theatre, opera and galleries," and "a leader in world fashion [that] offers a vast array of options for 'shopaholics' from discount designer outlets outside the city to huge department stores, from reasonably priced chain stores on local high streets to one-off boutiques and bustling markets." Impact Teachers gushes, "Living in London provides such a variety of locations to live and things to do, it can be mindboggling to know where to start! As the famous writer Samuel Johnson said, 'When you're tired of London, you're tired of life!'” 
Images on some of the websites reinforce this message. Time Plan's website, for example, shows a young man sitting on the beach under an umbrella beside a graphic of the London skyline, and the Treble One Education site includes a photo gallery of "ballooning over London." The ITP Education website features cartoon panels of teachers. One panel depicts Tanya: "a primary teacher from Sydney," "a self-confessed hedonist, living life to the full" and a young woman on a "mission to socialize with swarthy, square-jawed, athletic and cosmopolitan men who can cook!" Tanya's "supply-teaching keeps her comfortably afloat [in London] so that she can afford to indulge herself and even put a little cash aside for travel." Another panel depicts Issac: "a typical ITP teacher" who has been teaching abroad but now is back "to spy out the land." Issac has "signed up for a paint-ball session with some other ITP teachers," including "oddly enough, ... an Aussie called Tanya" who "appears to have taken an inexplicable shine to him."

Importantly, what one does not find amidst these allusions to travel, adventure, and romance are either frank discussions about the realities of teaching abroad or appeals to a professional ethic grounded in an understanding of children's educational needs. There are exceptions, of course. The Renaissance Education website (unlike any other reviewed) speaks forthrightly about the challenges involved in teaching abroad:

It is a tough job for which not everyone is suited. And nowhere is it tougher than in London ... Imagine ...

- 32 London boroughs, each running its education service in accordance with local needs and priorities

- A population with exceptionally diverse backgrounds - ranging from Afro-Caribbean, to Asian, Chinese and African

- Highly challenging behaviour - so that classroom management is the first key skill you will need ....

Could you cope with this? Many teachers can't....

Despite this candidness, an exception to the rule, the online teacher-recruitment agencies overall are selling schools a low-cost, low-hassle "solution" to their teacher shortage problems while, in many cases, encouraging teachers to see registration as a first step to a fun-filled life of travel and adventure.

\section{Recommendations and conclusion}

As we said, we did not set out to resolve the question of whether South Africans should be recruited to teach in the UK or of whether online recruitment is desirable, but rather to understand how teachers are being recruited. Marketing professors Philip Kotler and Gary Armstrong $(2006,6)$ advise agencies as a first step "to understand customer needs and wants and the marketplace within which they operate." Assuming the online teacher-recruitment agencies have done this homework, their assumptions about "customer needs and wants" are clear: Schools need teachers who can do the job without causing problems or costing too much money, and teachers want employment, preferably in schools and locales that offer opportunities or satisfactions above and 
beyond the basic wages. Not surprisingly, therefore, many agencies promise schools thorough vetting of candidates and low fees, invite teachers to imagine an exciting life outside the classroom as well as good pay, and assure both that the agency can make the "right" match.

However, as Kotler and Armstrong (2006) suggest, understanding customer needs and wants as well as the market is not enough. "Enlightened marketing" requires companies also to consider both consumers' and the broader society's "long-run interests" (Kotler and Armstrong 2006, 11). Based on our review of the 43 websites and analysis of the agencies' marketing strategies, we question how well the short-term matching of schools' and teachers' needs and wants, however efficient or "friendly" the process, is addressing prospective teachers' need to gain an adequate understanding of what teaching abroad may entail.

We therefore offer this recommendation to teachers seeking to affiliate with an online teacher-recruitment agency: Study the websites of agencies with the Quality Mark before considering teaching in the UK. These websites are more complete and informative than the websites of agencies without the Quality Mark. In this study, 50 out of 52 items were more frequently indicated on the websites of agencies with the Quality Mark.

For the online teacher-recruitment agencies, we also have some recommendations, based on a concern for the well-being of the teachers:

- Apply for the DfES Quality Mark if you do not have it, and reapply before it expires if you do.

- Ensure that your website is updated at least once a year.

- Provide updated pay scales for permanent and supply teachers, with and without QTS.

- Provide adequate information about the costs of living in the UK, about teaching and social support, and about the UK education system.

- Consider adding English proficiency and at least one year's teaching experience as criteria in the vetting of teachers.

- Include email addresses of teachers whose testimonials are quoted, if possible, so that prospective applicants can contact them.

\section{Notes}

1. These agency websites were reviewed: Academics Ltd, A Star Teachers, Axcis, Beacon Education Ltd, Blue Wave International Ltd, Capita Education Resourcing, Career Teachers, Classroom Call Education Services, Classroom Teachers, Connaught Education, DLK Recruitment, Dream Education, Global Education, GSL Education, Headline Teachers, Hays Education, Impact Teachers, ITN Mark Education, ITP Education Resourcing, Justteachers, London Education Recruitment, Master Lock Recruitment, NP Teaching, Opus Educational, Premiere Education, Primary Supply, Protocol Education, Renaissance Education, Sanza Teaching Agency Ltd, SA-Recruitment, Semester Recruitment, Supply \& Demand, Supply Desk, Teach London, Teachers UK, Teaching Personnel Ltd, Teachweb, The Education Network, Time Plan, Tradewind Recruitment, Treble One Education, Trust Education, and Verity Education.

\section{References}

Appleton, S., W.J. Morgan, and A. Sives. 2006. Should teachers stay at home? The impact of international teacher mobility. Journal of International Development 18: 771-86. 
Asmal, K. 2004. South Africa's brain drain dilemma. BBC News. http://news.bbc.co.uk/1/hi/ world/africa/3629657.stm.

Bernstein, Ann. 2007. Skills, growth, and migration policy: Overcoming the "fatal constraint". Johannesburg: The Centre for Development and Enterprise.

Bertram, Carol, V. Wedekind, and N. Muthukrishna. 2007. Newly qualified South African teachers: Staying or leaving? Perspectives in Education 25, no. 1: 77-89.

Bolowana, Angela. 2005. Trainee teachers eye overseas jobs. The Mercury. http:// www.themercury.co.za/index.php?fSectionId=2816\&fArticleId=2461992.

Busani, Dudu. 2008. Foreign teachers for SA. Sowetan, April 7.

Department for Education and Skills. 2004. A quality mark scheme for agencies and LEAs: Providing supply teachers to schools in England. http:/www.teachernet.gov.uk/ supplyteachers/downloads/documents/ACAF4746.pdf.

De Villiers, J.J.R. 2004. South African teachers in United Kingdom schools: Expectations and experiences. Journal of Educational Studies 3, no. 1: 49-66.

Govender, Pegra. 2007. Foreigners recruited to ease maths, science crisis. Sunday Times, September 30.

Jansen, Herman. 2002. Britte sukkel erg met dissipline in hul skole. Rapport, April 28.

Kotler, Philip, and Gary Armstrong. 2006. Principles of marketing. New Delhi: Prentice-Hall of India.

Kruger, Carien. 2008. Skole sal self onnies moet probeer werf. Rapport, March 16.

MacGregor, K. 2008. South Africa: Government may re-create teacher colleges. University World News, April 27. http://www.universityworldnews.com/article.php?story=2008042 7091640134.

Manik, S. 2007. To greener pastures: Transnational teacher migration from South Africa. Perspectives in Education 25, no. 2: 55-65.

McNamara, Olwen, Sarah Lewis, and John Howson. 2005. The recruitment of overseas trained teachers. Research Report conducted on behalf of NASUWT. Birmingham, UK: NASUWT.

McNamara, Olwen., Sarah Lewis, and John Howson. 2007. "Turning the tap on and off”: The recruitment of overseas trained teachers to the United Kingdom. Perspectives in Education 25, no. 2: 39-54.

Miller, P.W. 2007. "Brain gain" in England: How overseas trained teachers have enriched and sustained English education. Perspectives in Education 25, no. 2: 25-37.

Morgan, William J., Amanda Sives, and Simon Appleton. 2006. Report of the teacher mobility, "brain drain", labour markets and educational resources in the Commonwealth. London: Commonwealth Policy Studies Unit.

Mulvaney, G. 2005. Marketing ethics: The recruitment of South African teachers by British teacher recruitment agencies. Johannesburg: Institute of Marketing.

News 24. 2005a. Teaching overseas "precarious." http://www.news24.com/News24/ South_Africa/News/0,2-7-1442_1738181,00.html.

News 24. 2005b. UK discourages SA teachers. http://www.news24.com/News24/ South_Africa/News/0,2-7-1442_1738181,00.html.

Ochs, Kimberly. 2003. A summary of "Teaching at Risk" - Teacher mobility and loss in Commonwealth member states. A study commissioned by the Commonwealth Secretariat Education Section at the request of Ministers of Education of the Commonwealth Caribbean. London: Commonwealth Secretariat.

South African Broadcasting Corporation Special Assignment. 2004. Lessons abroad. http:// www.sabcnews.com/specialassignment/lessons.html.

Sutherland, H., and S. Rees. 1995. Wasted lives? Access to the profession for overseas trained teachers. Adults Learning (England) 7, no 1: 17-19. 